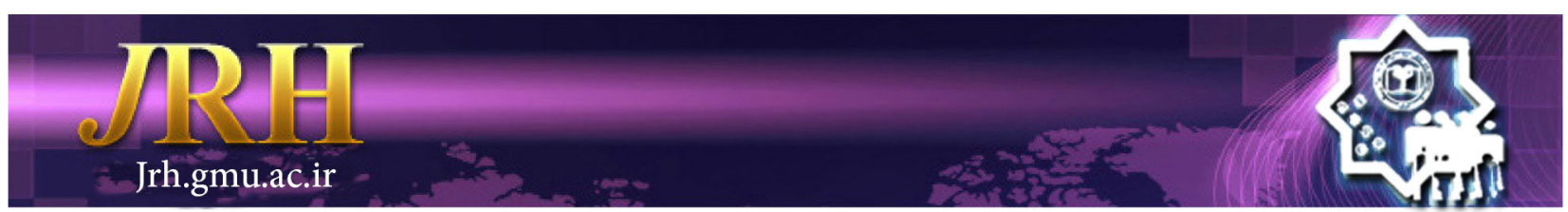

\title{
Predicting coping self-efficacy based on social support, personal growth, and mindfulness in people with cancer
}

\author{
Ruhollah Saranjam ${ }^{1}$, Abdollah Forouzanfar ${ }^{2}$, Abdolvahab Samavi ${ }^{3}$
}

\author{
Journal of Research \& Health \\ Social Development \& Health Promotion \\ Research Center \\ Vol. 9, No.4, Jul \& Agu 2019 \\ Pages: $363-370$ \\ DOI: $10.29252 / j r h .9 .4 .363$ \\ Original Article
}

1. Department of Midwifery, Faculty of Nursing and Midwifery, Mother and Child Welfare Research Center, Hormozgan University of Medical Sciences, Bandar Abbas, Iran

2. Department of Theology, Faculty of Humanities, University of Hormozgan, Bandar Abbas, Iran

3. Correspondence to: Department of Educational Sciences, Faculty of Humanities, University of Hormozgan, Bandar Abbas, Iran

Email: wahab.samavi@gmail.com

Received: 30 Oct 2018

Accepted: 10 Dec 2018

How to cite this article: Saranjam R, Forouzanfar A, Samavi A. Predicting coping self-efficacy based on social support, personal growth, and mindfulness in people with cancer. J Research \& Health2019; 9(4): $363-370$

\section{Introduction}

Attitudes play a vitally important role in guiding people's behavior toward goals, knowledge of their consequences and the effective processing of complex information about the living environment. taken together, attitudes of the people in a society toward social issues have been considered as the determiner of the people's intentions in dealing with social issues. One of the major matters in each community is the health of community. One of the most important and complex health issues in Iran is cancer. Patients with cancer often encounter two major problems. First, coping with symptoms of his/her illness, which can vary by type of the disease; these symptoms can affect the job, independent life and life satisfaction of these people. Second, adaptation to psychological symptoms of cancer (such as psychological stress, anxiety, depression, and etc). Even people who have well-controlled physical symptoms of their illness are also in difficult psychological adaptation to cancer. Getting informed about having cancer seems like a shock and traumatic experience for everyone. knowing about the life-threatening illness (cancer), people's perception of life changes, and the patient tries to adapt to this situation. In patients with cancer, access to appropriate 
support resources is effective in adapting to the disease [1].

Responses to stress events have been gone under the influence of some factors. Among these factors, we can refer to cognitive assessment, sense of control and social support [2]. Lazarus puts an emphasis on the interaction between the internal and external components of stress in stress cognitive theory. He believes an individual's perspective about a situation determines whether it is a stressful event or not. In the Lazarus exchange theory, cognitive evaluation is a two-part process which consists of the first and secondary evaluation. The first evaluation is the process of understanding the meaning of the event and its positive and negative outputs (threat assessment, challenge, and loss). The secondary evaluation occurs after the event and it is a perception a threat or challenge. During this process, the individual examines his or her personal and social resources and facilities for coping with stress [3].

One of the cognitive variables that play a vitally important role in coping with stress is self-efficacy. Self-efficacy is defined as one's confidence about his ability to perform certain behaviors. According to the theory of selfefficacy, individual beliefs about the successful conduct of a behavior determine its effort to engage in that behavior [4]. Therefore, selfefficacy generally refers to individual beliefs about the production of any desired outcome, while coping self-efficacy refers, in particular, to the individual's ability to effectively deal with difficult or threatening events, such as a disease or economic crisis [5]. Having higher coping self-efficacy can promote behavioral and emotional engagement to regulating psychological distress. This variable is under the influence of some cognitive and social predictors [6]. In the present study, three of these variables have been studied.

Social support is one of the key determinants of coping with illness-related stress. This structure is widely regarded as a multidimensional construct that reflects the individual's perception of a variety of information as well as emotional and instrumental support that a person receives from members of the social network such as family and friends [7]. Studies have shown that perceived social support and coping strategies have a great bearing on positive adaption to disease $[7,8]$. The role of perceived social support, integrating to groups and group social support have been confirmed in reducing stress and positive coping with disease among cancer patients [7].

The method of the evaluation and the sense of control is a variable that plays an important role in the personal growth of the individuals. Benefiting individuals from these abilities can increase their personal growth and help them cope with stress. The term "Personal Growth Innovative" (PGI) has been proposed by Robitschek [9] to characterize an active and deliberate engagement in personal growth. Robitschek's PGI theory has two cognitive aspects (such as values and beliefs about personal growth) and behavioral (actions that aim to increase personal growth). Robitschek has developed the Personal Growth Initiative Scale (PGIS) to measure this structure. Recently, Robitschek et al [10], by modifying the theoretical and operational foundations of this structure, have developed a set of items to operationalize the behavioral and cognitive dimensions of this variable. Studies have shown that personal growth has meaningful relationships with the psychological functions of the individuals. For example, the study by DeFreitas et al [11] has shown the evidence of a relationship between personal growth and psychological well-being and mental wellbeing. The relationship between personal growth and coping potentials has also been supported [12-14]. It has been also revealed that personal growth is negatively related to psychological distress, trait anxiety, depression, post-traumatic stress symptoms, negative affect, and social anxiety [15-19].

Mindfulness is a cognitive variable that can affect the coping strategies and self-efficacy of using these strategies. This structure is rooted in Eastern spirituality and can be considered as one of the protection available sources for 
cancer patients [20]. Mindfulness can be defined as deliberate and imprecise attention at the moment and is regarded as an attitude towards emotion, curiosity, and kindness [21]. Garland et al [22] have offered a theory of mindfulness that describes the mindfulness mechanisms involved in positive evaluation of events and personal growth.

These researchers believe that the mindfulness leads the individual to a more positive assessment of the event by a kind of metacognitive ability. This positive assessment process also requires expanding the scope of the assessment to understand the positive experiences and turning it into personal growth and development. Moreover, this positive self-assessment, itself, produces positive emotions that may lead to adaptive sense of meaningfulness or purposefulness in life. Previous studies have shown that mindfulness can strengthen the mechanisms of coping with stress for patients and healthy individuals. For example, Garland, Gaylord, and Park [23] have shown that mindfulness can play a vitally important role in a positive re-evaluation, one of the components of coping with stress. These researchers describe a causal model of the underlying mindfulness mechanisms in effective coping strategies. In the same manner, Weinstein, Brown, and Ryan's study [24] has shown that individuals with high levels of mindfulness evaluate stress with low risk and use fewer avoidance strategies. These researchers have shown that more adaptive coping responses moderate the relationship between mindfulness and subjective well-being. Other studies have revealed that coping selfefficacy is predictable based on individual and interpersonal variables. Yu et al [25] has showed that positive coping strategies moderate the relationship between social support and posttraumatic development. These researchers have also shown that social support can improve coping strategies and promote personal growth in infertile women. Yazdani et al [26] have likewise investigated the relationship between the quality of marriage, social support, social acceptance and coping strategies in infertile women. The results of their study have shown that there is a positive relationship between coping strategies and social support. Furthermore, Künzler et al. [27] have addressed the role of personal growth in coping to cancer-related stress. These researchers have revealed that the personal growth of patients and their spouses can be affected by their coping capacities.

Considering the results of the new approaches and the emphasis on reducing the psychological effects of cancer, in the present paper, the role of social support, personal growth and mindfulness has been investigated in coping self-efficacy of cancer patients. Explaining the relationship between these variables as effective predictors of coping ability of patients can play an important role in designing interventional programs to increase their coping self-efficacy.

\section{Method}

The statistical population consists of all cancer patients referred to The hospital of Bandar Abbas city, in south of Iran, during the first half of 2017. 120 participants has been selected using available sampling method. The research objectives were explained to the participants in the research, and, having informed them all about the right to withdraw from the research, they completed the written consent for participation in the research.

For measuring social support, a multidimensional perceived social support questionnaire (Zimt et al.) [28] has been used. The authors of this questionnaire have designed it to measure perceived social support from the family, friends, and significant other of the individual. This scale has 12 items, and respondent specifies his/her opinion on a seven point's continuum. The range of scores for each item varies from "1" (Very Strongly Disagree) to "7" (Very Strongly Agree). A higher score on this scale reflects higher perceived social support. Validity and reliability of this questionnaire have been reported by its creators on a satisfactory level. Accordingly, the validity assessment of this questionnaire confirms its three-factor structure by the factor analysis method. Also, the reliability 
coefficients of this questionnaire for the whole scale and the subscales of significant other, family and friends are reported to be $0.88,0.91$, 0.87 and 0.85 , respectively [28]. The reliability of this scale in Iran has been reported for total social support, significant other, family and friends $0.89,0.84,0.85$ and 0.91 , respectively [29]. In the present study, the coefficients of reliability for the overall scale, significant other, family and friends are calculated 0.84, $0.87,0.81$ and 0.86 , respectively.

Personal Growth is measured by Robitschek's personal growth initiative scale. This questionnaire is created by Robitschek [30], which has 9 items and aims to examine the individual growth components (4 components). The questionnaire is based on Likert scale, with a range from 1 to 5 , and its score range is from 9 to 45. A higher score indicates a higher personal growth. Robitschek [30] reported the reliability of this scale 0.78 to 0.88 with the Cronbach's alpha method, and with a testretest method running on a student sample with eight weeks interval, it is equal to 0.74 . Also, the convergent validity of this questionnaire has been confirmed by calculating the positive correlation coefficient with the internal locus of control and conscious growth scores $(0.24$ to 0.56 ) and its divergent validity approved by calculating the negative correlation coefficient with the external locus of control and the unconscious growth scores $(-0.24$ to -0.56$)$ [30,31]. In Iran, the reliability of this scale has been reported as 0.89 [32]. Likewise, the reliability of this scale is calculated as 0.84 in the present study.

The coping self-efficacy was estimated by the Chesney et al. coping self-efficacy questionnaire [5]. This scale measures the positive and effective coping and focuses on one's trust in his ability to effective coping and is developed in accordance with Bandura's self-efficacy theory. This scale has 26 items and has a 3 -point Likert responding scale, so that the "I cannot do at all" option is zero, with the option "Moderately I Can Do", a score of one to five and the "I can always do" option is awarded a score of 5 to 10 . From this, the range of scores varies from zero to 260 . The validity of the original version has been verified by the developers through the exploratory and confirmatory factor analysis method, and its three-factor structure is confirmed. Additionally, the reliability coefficients for the three factors of problem-oriented coping, emotional coping and receiving support from friends and family are reported to be 0.91, 0.91 and 0.80 respectively [5]. Validity and reliability of this questionnaire in Iran has been investigated by Bahramian et al. [33] and its validity is confirmed by exploratory factor analysis and confirmatory factor analysis. Also, the results of Bahramian et al. study shows that the coefficients of reliability for the factors of this questionnaire are obtained from 0.63 to 0.91 [33]. To test the research hypothesis, multiple regression analysis is used in Enter method. Before analyzing data, the assumptions for using multiple regression including data normalization, Multicollinearity and absence of outliers are investigated.

\section{Results}

The research has been conducted on 120 cancer patients. The mean and standard deviation of the age in the total participants, female and male, were 39.4, 42.7 and 36.1, respectively. $73(60.8 \%)$ of were men and $47(39.2 \%)$ of it are female. The descriptive findings of the research variables are presented in Table 1 and the correlation matrix of the variables are demonstrated in Table 2.

\begin{tabular}{lcccc} 
Table 1 Descriptive statistics of research variables \\
\hline Variable & Mean & SD & Min & Max. \\
\hline Social support & 36.39 & 12.86 & 18 & 64 \\
Personal growth & 23.48 & 7.51 & 12 & 40 \\
Mindfulness & 29.45 & 8.77 & 18 & 49 \\
Coping self-efficacy & 132.29 & 19.88 & 98 & 171 \\
\hline
\end{tabular}


Table 2 Correlation matrix of research variables

\begin{tabular}{lccc}
\hline Variable & Social Support & Personal growth & Mindfulness \\
\hline Personal growth & $0.63^{* *}$ & & \\
Mindfulness & $0.23^{* *}$ & $0.23^{* *}$ & \\
Coping self-efficacy & $0.62^{* *}$ & $0.75^{* *}$ & $0.33^{* *}$ \\
\hline$* * \mathrm{p}<0.01$ & & &
\end{tabular}

The main hypothesis of the research refers to the relationship between social support, personal growth and mindfulness with coping self-efficacy in people with cancer. Normality of data has been tested by KolmogorovSmirnov Test.

Table 3. The results of the Kolmogorov-Smirnov test on the normalization of data

\begin{tabular}{lcl}
\hline Variable & $\mathrm{Z}$ & Sig. \\
\hline Social support & 1.03 & 0.23 \\
Personal growth & 1.08 & 0.27 \\
Mindfulness & 1.12 & 0.32 \\
Coping self-efficacy & 1.01 & 0.21 \\
\hline
\end{tabular}

The significance level of the KolmogorovSmirnov test for all variables is higher than 0.05 , indicating the normality of the data. Multiple regression results have been demonstrated in Table 4. Social support, personal growth and mindfulness have been accounted for $60 \%$ of the variance of coping self-efficacy. Beta values for variables indicate social support (beta $=0.22)$, personal growth $($ beta $=0.57)$, and mindfulness (beta $=0.14$ ) correlated with coping self-efficacy positively and significantly in cancer patients.

Table 4 Multiple regression results to predict coping self-efficacy via social support, personal growth and mindfulness

\begin{tabular}{lccccccccc}
\hline Variables & B & S.E. & Beta & T & $p$ & R & Adj. $R^{2}$ & F & $p$ \\
\hline Constant & 73.56 & 5.03 & - & 14.60 & 0.001 & & & & \\
Social support & 0.34 & 0.12 & 0.22 & 2.94 & 0.004 & & & & \\
Personal growth & 1.56 & 0.21 & 0.57 & 7.58 & 0.001 & 0.78 & 0.60 & 60.73 & 0.001 \\
Mindfulness & 0.32 & 0.14 & 0.14 & 2.38 & 0.01 & & & & \\
\hline
\end{tabular}

\section{Discussion}

The purpose of this study is to predict coping self-efficacy based on social support, personal growth and mindfulness in cancer patients. This result has further strengthened our research hypothesis that confirmed and social support, personal growth and mindfulness predicted the coping self-efficacy, positively and significantly. The most interesting result to emerge from the data is that the research model was able to be account for $60 \%$ of the variance of coping selfefficacy. The results obtained in this study are in line with the findings of previous researches [8,13,15,23]. For example, Bruent et al. [7] have shown that social support can play an effective role in coping with cancer-related stress in patients undergoing treatment. There is also a significant relationship between positive coping strategies and social support and post traumatic growth in Yu et al. study [25]. These researchers have shown that social support can improve coping strategies and personal growth. Along with the results of this study, Yazdani et al. [26] also has pointed to the significant relationship between quality of marriage, social support, social acceptance and coping strategies in infertile women. The results of their study have shown that there is a positive relationship between coping strategies and social support. Study of Künzler et al. [27] has also supported the role of personal 
growth in coping with cancer-related stress. The researchers have shown that the personal growth of patients and their spouses can be affected by coping potentials.

The findings of the present study, consistent with the results of earlier studies, showed that each of the predictive variables could predict coping self-efficacy in cancer patients, positively and significantly. A very close look at the beta coefficients shows that personal growth has the highest, and the mindfulness has the lowest predictive power.

In clarifying the results, we can allude to Bandura's self-efficacy theory and the theoretical foundations in this field. As indicated by Bandura, self-efficacy beliefs are shaped by data sources. One of the solid information sources impacting self-efficacy beliefs is the individual's personal experiences of achievements and failures in a particular context. As the aftereffects of the exploration demonstrated that personal growth-a variable associated with personal experiences has the most elevated potential in anticipating self-efficacy. In other words, personal experience of patients in helping their personal growth has possessed the capacity to fortify their selfefficacy beliefs. As per Chesney [5], coping self-efficacy refers to a person's confidence in his ability to effectively deal with difficult or threatening events such as ailment. Individuals with coping self-efficacy believe that they can resist the progression of the disease and use it as an opportunity for personal growth.

Another resource of information about selfefficacy is vicarious experiences, and the effects of others on individuals. The results of this study showed that perceived social support could predict coping self-efficacy, positively and significantly. Interacting with others, especially significant other, and models, has a significant effect on the formation and strengthen of selfefficacy beliefs. The results of this study showed that people with higher social support have been able to improve self-efficacy. The belief in these people is that if others succeed in enduring the disease, their chances of success will be high.

The results of this paper show that higher mindfulness leads to higher coping self- efficacy in the individual. One of the possible explanations is the nature of the coping ability of mindfulness. Those who have high mindfulness have purposeful and unconditional attention to the moment. Kabat-Zeinn [21] suggests that mindfulness by a kind of metacognitive ability leads the person to a more positive assessment of events. This positive assessment extends the scope of positive experiences perception and transforms it into development and personal growth. This positive assessment is a positive emotions producer that may lead to adaptive behaviors and a sense of meaning and purposefulness in life. Hence, mindfulness can improve the mechanisms of coping with stress in patients as well as healthy individuals.

Along with the findings, this study has some limitations that can affect the generalizations of the findings. One of the main limitations of the present study is the characteristics of the sample. It is suggested in future studies, samples of other cities and provinces should be studied. In this study, the type of cancer is not considered, and there are different types of cancers in the research sample. It is recommended that future studies shall be focused on a group of patients with specific cancer. Use of self-report questionnaires is one of the other limitations of this study. It is suggested in upcoming studies, other methods of collecting data, including interview, should be used to increase the validity of the results.

\section{Conclusion}

Taken together, the evidence from this study points towards the significant role of social support, personal growth and mindfulness in increasing the coping with self-efficacy in cancer patients. Considerable progress has been made to provide useful and practical implications about counseling and mental health promotion programs for cancer patients. Broadening the social support for cancer patients and designing interventions to increase their personal growth, as well as raising their level of mindfulness through practical interventions, can increase coping self-efficacy in these patients to deal with the psychological 
consequences of cancer.

\section{Acknowledgments}

The authors of the paper appreciate the gratefully acknowledge the all samples that assisted the research team.

\section{Authors' contributions}

Study design: SAS

Collecting and analyzing data: RS

Manuscript preparation: AF

All authors have read and approved the final version.

\section{Conflict of Interest}

"The authors declare that they have no competing interests."

\section{Funding}

The author (s) received no financial support for the research.

\section{Availability of data and materials}

The datasets used and/or analyzed during this study are available from the corresponding author on reasonable request.

\section{References}

1- Willener R, Hantikainen V. Individual quality of life following radical prostatectomy in men with prostate cancer. Urol Nurs2005; 25(2): 88-100.

2- Folkman S. Personal control and stress and coping processes: A theoretical analysis. J Pers Soc Psychol1984; 46(4): 839-52.

3- Lazarus RS. Coping theory and research: past, present, and future. Fifty years of the research and theory of RS Lazarus: An analysis of historical and perennial issues. 1993:366-88.

4- Bandura A. The science of health promotion. Am $J$ Health Promot1997; 12(1): 8-10.

5- Chesney MA, Neilands TB, Chambers DB, Taylor JM, Folkman S. A validity and reliability study of the coping self-efficacy scale. Br J Health Psychol2006; 11(3): 421-37.

6- Schwarzer R, Renner B. Social-cognitive predictors of health behavior: action self-efficacy and coping selfefficacy. Health Psychol2000; 19(5): 487.

7- Brunet J, Love C, Ramphal R, Sabiston CM. Stress and physical activity in young adults treated for cancer: the moderating role of social support. Support Care Cancer2014; 22(3): 689-95.
8- Dukes Holland K, Holahan CK. The relation of social support and coping to positive adaptation to breast cancer. Psychol Health2003; 18(1): 15-29.

9- Robitschek C. Life/career renewal: An intervention for vocational and other life transitions. J Career Dev1997; 24(2): 133-46.

10- Robitschek C, Ashton MW, Spering CC, et al. Development and psychometric evaluation of the personal growth Initiative Scale-II. J Couns Psychol2012; 59(2): 274.

11- de Freitas CP, Damásio BF, Tobo PR, Kamei $\mathrm{HH}$, Koller SH. Systematic review about personal growth initiative. Anales de Psicologia/Annals of Psychology2016; 32(3): 770-82.

12- Pollard C, Kennedy P. A longitudinal analysis of emotional impact, coping strategies and post-traumatic psychological growth following spinal cord injury: A 10-year review. Br J Health Psychol2007; 12(3): 34762.

13- Gall TL, Charbonneau C, Florack P. The relationship between religious/spiritual factors and perceived growth following a diagnosis of breast cancer. Psychol Health2011; 26(3): 287-305.

14- Schmidt SD, Blanl TO, Bellizzi KM, Park CL. Posttraumatic growth reported by emerging adults: a multigroup analysis of the roles of attachment, support, and coping. Curr Psychol2017: 1-10.

15- Ayub N Iqbal S. The relationship of personal growth initiative, psychological well-being, and psychological distress among adolescents. J Teach Phys Educ2012; 1(6): 101-7.

16- Ogunyemi AO, Mabekoje SO. Self-efficacy, risktaking behavior and mental health as predictors of personal growth initiative among university undergraduates. Rev Electron Investig Psicoeduc Psigopedag2007; 5(12): 349-362

17- Weigold IK, Robitschek C. Agentic personality characteristics and coping: Their relation to trait anxiety in college students. Am J Orthopsychiatry2011; 81(2): 255-64.

18- Hardin EE, Weigold IK, Robitschek C, Nixon AE.Self-discrepancy and distress: The role of personal growth initiative. J Couns Psychol2007; 54(1): 86-92.

19- Vandenberghe L, Costa Prado F. Law and grace in Saint Augustine: a fresh perspective on mindfulness and spirituality in behaviour therapy. Ment Health Relig Cult2009; 12(6): 587-600.

20- Kabat-Zinn J. Mindfulness-based interventions in context: past, present, and future. Clin Psychol SCI PR2003; 10(2): 144-56.

21- Garland EL, Farb NA, Goldin P, Fredrickson BL. Mindfulness broadens awareness and builds eudaimonic meaning: A process model of mindful positive emotion regulation. Psychol Inq2015; 26(4): 293-314. 
22- Garland E, Gaylord S, Park J. The role of mindfulness in positive reappraisal. Explore2009; 5(1): 37-44.

23- Weinstein N, Brown KW, Ryan RM. A multi-method examination of the effects of mindfulness on stress attribution, coping, and emotional well-being. $J$ Res Pers2009; 43(3): 374-85.

24- Yu Y, Peng L, Chen L, et al. Resilience and social support promote posttraumatic growth of women with infertility: The mediating role of positive coping. Psychiatry Res2014; 28; 215(2): 401-5.

25- Yazdani F, Kazemi A, Fooladi MM, Samani HR. The relations between marital quality, social support, social acceptance and coping strategies among the infertile Iranian couples. Eur J Obstet Gynecol Reprod Biol2016; 200: 58-62.

26- Künzler A, Nussbeck FW, Moser MT, Bodenmann G, Kayser K. Individual and dyadic development of personal growth in couples coping with cancer. Support Care Cancer2014; 22(1): 53-62.

27- Zimet GD, Dahlem NW, Zimet SG, Farley GK. The multidimensional scale of perceived social support. $J$ Pers Assess 1988; 52(1): 30-41.

28- Bagherian-Sararoudi R, Hajian A, Ehsan HB, Sarafraz
MR, Zimet GD. Psychometric properties of the Persian version of the multidimensional scale of perceived social support in Iran. Int J Prev Med2013; 4(11): 1277-81.

29- Robitschek C. Further validation of the ersonal growth initiative Scale. Meas Eval Couns Dev1999; 31(4): 197-210.

30- Robitschek C. Validity of personal growth initiative scale scores with a Mexican American college student population. J Couns Psychol2003; 50(4): 496-502

31- Abolghasemi, A, Moradisrosh MN, Narimay M, Zahed A. The relationship between personal initiative, religious orientation and organizational social capital and workers job performances in the productive centers. Knowledge \& Research in Applied Psychology2011; 12(1): 86-94.

32- Walach H, Buchheld N, Buttenmüller V, Kleinknecht N, Schmidt S. Measuring mindfulness-the freiburg mindfulness inventory (FMI). Pers Individ Dif2006; 40(8): 1543-55.

33- Bahramiyan AF, Morovati Z, Yosefiafrashte M, Amiri M. Reliability, validity, and factorial analysis of coping self-efficacy scale. Clinical Psychology \& Personality2017; 15(2): 215-26.

Copyright $($ C 2016 ASP Ins. This open-access article is published under the terms of the Creative Commons Attribution-NonCommercial 4.0 International License which permits Share (copy and redistribute the material in any medium or format) and Adapt (remix, transform, and build upon the material) under the Attribution-NonCommercial terms. 